\title{
Reduction Mechanism of Fine Hematite Ore Particles in Suspension
}

\author{
ZHIYUAN CHEN (D, CHRISTIAAN ZEILSTRA, JAN VAN DER STEL, JILT SIETSMA, \\ and YONGXIANG YANG
}

In order to understand the pre-reduction behaviour of fine hematite particles in the HIsarna process, change of morphology, phase and crystallography during the reduction were investigated in the high temperature drop tube furnace. Polycrystalline magnetite shell formed within $200 \mathrm{~ms}$ during the reduction. The grain size of the magnetite is in the order of magnitude of $10 \mu \mathrm{m}$. Lath magnetite was observed in the partly reduced samples. The grain boundary of magnetite was reduced to molten $\mathrm{FeO}$ firstly, and then the particle turned to be a droplet. The Johnson-Mehl-Avrami-Kolmogorov model is proposed to describe the kinetics of the reduction process. Both bulk and surface nucleation occurred during the reduction, which leads to the effect of size on the reduction rate in the nucleation and growth process. As a result, the reduction rate constant of hematite particles increases with the increasing particle size until $85 \mu \mathrm{m}$. It then decreases with a reciprocal relationship of the particle size above $85 \mu \mathrm{m}$.

https://doi.org/10.1007/s11663-021-02173-y

(C) The Author(s) 2021

\section{INTRODUCTION}

THE reduction and melting behavior of fine iron ore particles above $1573 \mathrm{~K}$ are rarely studied. In recent years, along with the development of a novel alternative ironmaking process, researchers started to pay attention to this topic. Tata Steel Europe has been developing HIsarna process to reduce carbon emission and energy since $2004 .^{[1,2]}$ A smelting cyclone part was employed here for pre-reduction and melting of fine iron ore particles. $\mathrm{Qu}$ et al. studied the reduction and melting behavior of hematite ore particles in the temperature range from $1550 \mathrm{~K}$ to $1750 \mathrm{~K}^{[3-5]}$ They studied the effect of gas composition and particle size on the reduction kinetics. The experimental results show that the reduction degree at a given time linearly decreases with the increase of particle size. Moreover, the reduction rate constant at $1650 \mathrm{~K}$ has a positive linear relationship with the partial pressure of reducing gas,

ZHIYUAN CHEN is with the Department of Materials Science and Engineering, Delft University of Technology, Mekelweg 2, 2628 CD Delft, The Netherlands and also with the Separation and Conversion Technology, Flemish Institute for Technological Research, 2400 Mol, Belgium. Contact e-mail: aha c@126.com, zhiyuan.chen@vito.be CHRISTIAAN ZEILSTRA and JAN VAN DER STEL are with the Tata Steel in Europe, PO Box 10000, 1970 CA IJmuiden, The Netherlands. JILT SIETSMA and YONGXIANG YANG are with the Department of Materials Science and Engineering, Delft University of Technology.

Manuscript submitted November 13, 2021; accepted April 5, 2021.

Article published online May 10, 2021.
$\mathrm{CO}$ and $\mathrm{H}_{2}$. It is noted that the reduction process of hematite particles can be divided into three types: gas-solid particle reaction, gas-solid-melts mixed reaction and gas-molten droplet reaction. ${ }^{[5]}$ Most of the previous studies focus on the reduction kinetic study of gas-solid reaction. Yingxia et al. ${ }^{[6]}$ reported the reduction kinetics of gas-molten droplet reaction. Guo et al. ${ }^{[7]}$ presented the morphology and phase transformation of hematite particles in a molten state. Despite this, there is still a lack of experimental data for this type of reaction. Particularly, the reduction behavior of ore is closely related to the natural character, such as mineralogy and texture ${ }^{[8-10]}$ Studies of the reduction kinetics of different ores are necessary for a comprehensive knowledge.

Phase transformation inside the ore particles was investigated in this study. The reasons for reaction rate variation were discussed based on the results of morphology, chemical composition and crystallography. The kinetic models were discussed and the reaction mechanism was explored.

\section{EXPERIMENTAL}

High-temperature Drop Tube Furnace (HDTF) was employed as an experimental set-up in this study. The details of the furnace were described in References 3 and 11. Commercial hematite ore particles - which were provided by Tata Steel in IJmuiden - was reacted with $\mathrm{CO}-\mathrm{CO}_{2}$ gas in HTDF. There were atmospheres with two different reducing potentials: one was with $\mathrm{CO}: \mathrm{CO}_{2}$ $=5: 95$ in mole ratio, the other was with $\mathrm{CO}: \mathrm{CO}_{2}=$ 
45: 55 in mole ratio. They are representative of a typical range of reduction potentials in different areas of the smelting cyclone. The XRF (PANalytical Axios Max sequential wavelength dispersive X-Ray Fluorescence spectrometer) analysis result of the ore particles is shown in Table I. Ore with different particle sizes was prepared for the experiment. The average sizes of particles are 67, 85, 110, 142 and $244 \mu \mathrm{m}$. During the experiment, ore particles were fed from the top of HDTF, to react with gas in the hot zone, then collected by the sampling probe. An equation, developed from the study of Qu et al. ${ }^{[11,12]}$ is employed for the calculation of the residence time:

$$
\begin{aligned}
L= & u_{g} t+\frac{d_{p}^{2} g}{18 \mu_{g}}\left(\rho_{p}-\rho_{g}\right) t+\left[\left(u_{g}-u_{p}^{0}\right)+\frac{d_{p}^{2} g}{18 \mu_{g}}\left(\rho_{p}-\rho_{g}\right)\right] \\
& \frac{d_{p}^{2} \rho_{p}}{18 \mu_{g}}\left[\exp \left(-\frac{18 \mu_{g} t}{d_{p}^{2} \rho_{p}}\right)-1\right]
\end{aligned}
$$

where $L$ is the length of the reacting zone in the furnace, $\mu_{g}$ is the viscosity of the gas, $\operatorname{Re}$ is the Reynolds number of the particle, $g$ is the gravity, $u_{p}^{0}$ is the initial velocity of the particle, $u_{g}$ is the velocity of the reacting gas, $u_{p}$ is the falling velocity of a particle in the reactor, $d_{p}$ is the particle diameter, $\rho_{p}$ is the particle density, and $t$ is the falling time. The falling time is controlled by the velocity of the reacting gas. Reynold's number was estimated before experiments to ensure the flow in the reactor was a laminar flow. It is a simplified equation which only takes account into the effect of the most important factors on the residence time, and a detailed discussion of this formula can be referred to. ${ }^{[3,12]}$

The reaction temperature was set to be $1735 \mathrm{~K}$. The reduction degree of the partially reduced sample was analyzed with ICP-AES (Inductively Coupled Plasma-Atomic Emission Spectrometry) and chemical titration. ICP was employed to testify the mass ratio of total iron $(\mathrm{TFe})$. The titration method of $\mathrm{Fe}^{2+}$ follows the ASTM standard test method with the designation number of D 3872-05 (2005). The reduction degree $R$ of hematite ore is defined as the ratio of mass loss of oxygen to the total initial mass of oxygen in $\mathrm{Fe}_{2} \mathrm{O}_{3}$ in the ore, which can be calculated from ${ }^{[13]}$ :

$$
R=1-\frac{3\left(\mathrm{Fe}^{3+}\right)_{i}+2\left(\mathrm{Fe}^{2+}\right)_{i}}{3\left(\mathrm{Fe}^{3+}\right)_{0}+2\left(\mathrm{Fe}^{2+}\right)_{0}}=\frac{1}{3} \frac{\mathrm{Fe}^{2+}}{\mathrm{TFe}}
$$

where subscript $i$ presents the reduced product, 0 presents the raw material before the reduction. Equation [2] can be employed for the calculation of $R$ when the raw material doesn't contains any $\mathrm{Fe}^{2+}$ and the products contain no metallic iron inside.

The phase composition of the collected samples was detected by semi-quantitative XRD (Bruker D8 Advance X-Ray Diffraction) analysis. Optical microscope (Leica DMLM) was also employed to observe the morphology and phase distribution of the partially reduced particles. Crystallography of the typical sample was identified using Electro backscatter diffraction (EBSD, JEOL JSM 6500F).

\section{EXPERIMENTAL RESULTS}

\section{A. Morphology and Composition}

Hematite ore was partially reduced to suboxides in the specified atmospheres. Accorading to the thermodynamic analysis, ${ }^{[14,15]}$ these suboxides contained magnetite and liquid oxide, and the liquid oxide turned to wüstite in the quenching process. The partially reduced ore particles in resin were polished and investigated with an optical microscope. Figure 1 shows the ore reacted in $\mathrm{CO}: \mathrm{CO}_{2}(5: 95)$ atmosphere at $1735 \mathrm{~K}$. Different kinds of oxides can be distinguished by their color. Here they are introduced in the sequence from bright to dark: the part with bright color in micrographs is hematite, the part with bisque color is magnetite, the part with brown color is wüstite, and the region with a dark color is other minerals or quenched slag. Hematite cores within particles can be observed in Figure 1(b). Two kinds of un-reacted cores were observed in the partially reduced particles: The one was with a relatively smooth boundary with the magnetite shell; the other was with a feather-like phase boundary. The later one was the principal pattern of phase transformation during the reduction, and it indicated lath magnetite formed in the process. Lath magnetite is the magnetite that grows in the form of dense plates or laths inserting into the unreacted part. Usually, the formation of lath magnetite was reported below $1273 \mathrm{~K}$ with low reducing potential. ${ }^{[16,17]}$ This study extended the observed temperature range of lath magnetite formation to $1735 \mathrm{~K}$. The area of hematite core substantially shrunk with reaction time. Therefore, the hematite cores have disappeared, and turned into magnetite in most particles at $260 \mathrm{~ms}$. And then, the reaction seems to be slowing down after $260 \mathrm{~ms}$ for the reason of no apparent difference between Figures 1(c) and (d).

Except for hematite and magnetite phases, a small amount of wüstite has been observed in some particles which do not contain an un-reacted hematite core inside. It implies that the diffusion rate of oxygen inside the reacted part of the particle was relatively fast enough so that the oxygen potential in the reacted region kept homogenous in the reduction. Basically, the reaction interface is the gradient of oxygen potential. As a result, two reaction interfaces, hematite/magnetite interface and magnetite/ wüstite interface could not coexist simultaneously in one particle in our experimental conditions. Moreover, Figure 1 shows that wüstite invades into the particle as a thread. It implies that the magnetite formed in the particle is polycrystalline, and the grain boundary provides a channel for the reduction from magnetite to wüstite.

Morphologies of the ore particles which were partially reduced in $\mathrm{CO}: \mathrm{CO}_{2}(45: 55)$ atmosphere at $1735 \mathrm{~K}$ are shown in Figure 2. Unlike the particles in $\mathrm{CO}: \mathrm{CO}_{2}$ (5:95) atmosphere, they turned out to be a sphere in the reaction. The reason is that the main phase is wüstite in 
Table I. Chemical Composition of Hematite Ore Particles

\begin{tabular}{lcccccccc}
\hline Name & $\mathrm{Fe}_{2} \mathrm{O}_{3}$ & $\mathrm{SiO}_{2}$ & $\mathrm{Al}_{2} \mathrm{O}_{3}$ & $\mathrm{CaO}$ & $\mathrm{MgO}$ & $\mathrm{MnO}$ & $\mathrm{TiO}_{2}$ & Rest. \\
\hline (Wt Pct) & 72.35 & 14.03 & 4.99 & 2.97 & 2.52 & 1.43 & 0.72 & 0.98 \\
Error & 0.10 & 0.10 & 0.07 & 0.05 & 0.05 & 0.04 & 0.03 & \\
\hline
\end{tabular}
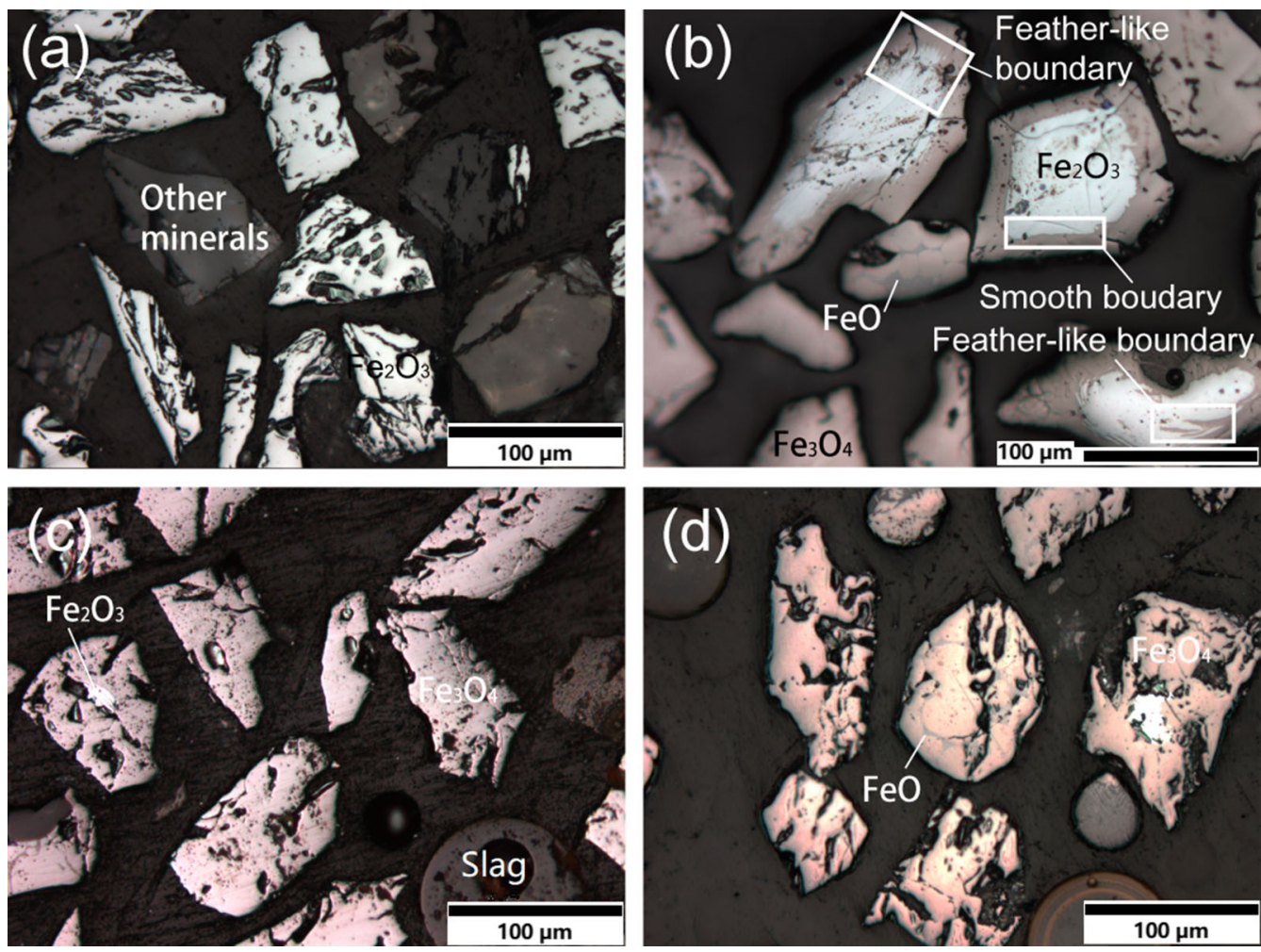

Fig. 1 - Cross-section of $(a)$ raw sample with an average size of $110 \mu \mathrm{m}$ and the samples reacted for $(b) 74 \mathrm{~ms}$; $(c) 260 \mathrm{~ms}$; and $(d) 320 \mathrm{~ms}$ in $\mathrm{CO}: \mathrm{CO}_{2}(5: 95)$ atmosphere at $1735 \mathrm{~K}$.

the samples. The melting point of $\mathrm{FeO}$ is $1650 \mathrm{~K}$. It is the only iron oxide that melts below the reaction temperature.

XRD results are employed to analyze the phase composition. Figure 3 shows the quasi-quantitative analysis results of the XRD pattern. For the convenience of comparison, the chemical analytical results of $\mathrm{Fe}^{2+} / \mathrm{TFe}$ are also plotted in the Figure 3. Particles partially reduced in $\mathrm{CO}: \mathrm{CO}_{2}$ (5:95) atmosphere mainly contained magnetite and rarely contained hematite. The content of wüstite was also limited in this atmosphere. Yet, the wüstite content in $\mathrm{CO}: \mathrm{CO}_{2}(45: 55)$ atmosphere increased to above 60 wt pct during reduction, becoming the principal phase composition of ore particles. At the same time, the low content of magnetite and hematite in the particles was also verified by XRD characterization.

Although the samples contain gangue materials, both Figures 1 and 2 show that most of the particles can be classified as gangue particles or iron-oxides particles. Usually, gangue particles have been melted and form slag in the reaction process, so most of them are spheres in the collected samples. We named the melted gangue as slag, and the un-melted gangue as other-minerals here. It also implies that the direct inter-reactions between gangue and iron-oxides can be ignored in the experiments. It is easy to understand the reason that a laminar flow was provided in the reactor to prevent agglomeration forms in the reaction. Appendix A provides a statistical analysis result as evidence of the independent reduction of iron-oxide particles. In the XRD spectrogram, slag was observed as a dispersing diffraction peak around $20^{\circ}$. The unfused minerals were difficult to see in XRD spectrogram because of their minor contents. The principal phases of other minerals were detected as the quartz and lime.

The phase composition of iron ore particles with other average sizes is shown in Figures 4, 5 and Table II. All the data of particles with an average size from 67 to $142 \mu \mathrm{m}$ shows that the value of $\mathrm{Fe}^{2+} / \mathrm{TFe}$ of samples reduced in $\mathrm{CO}: \mathrm{CO}_{2}(5: 95)$ is less than in $\mathrm{CO}: \mathrm{CO}_{2}(45: 55)$ atmosphere. Correspondingly, the mass ratio of $\mathrm{FeO}$ in the sample reduced in $\mathrm{CO}: \mathrm{CO}_{2}(5: 95)$ is less than in $\mathrm{CO}: \mathrm{CO}_{2}(45: 55)$ atmosphere. However, the reduced ore with an average size of $244 \mu \mathrm{m}$ shows no 

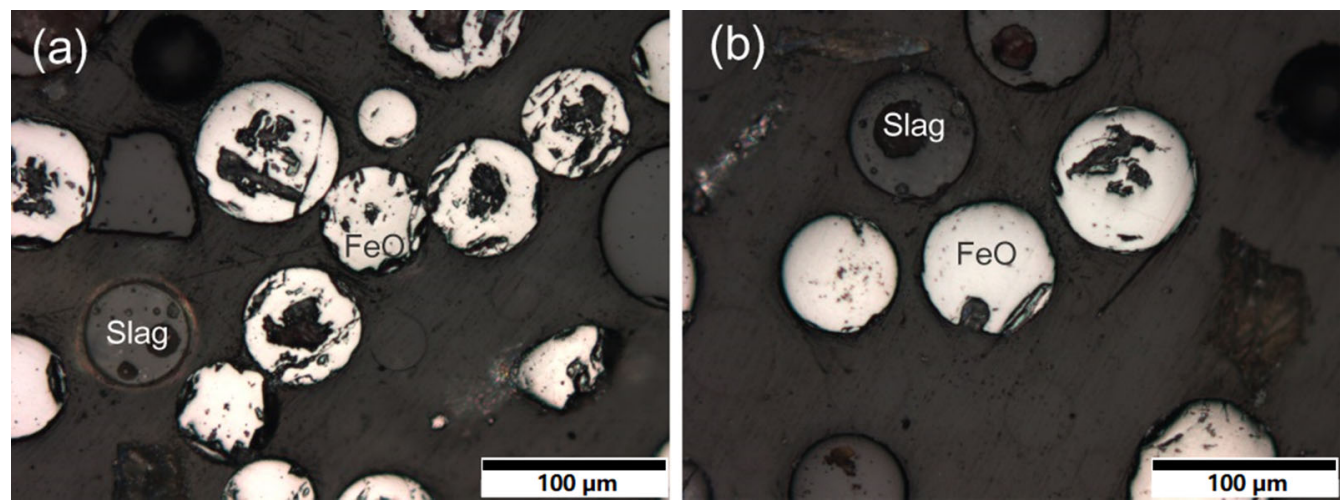

Fig. 2 - Cross section of samples with an average size of $110 \mu \mathrm{m}$ reacted for (a) $74 \mathrm{~ms}$ and (b) $159 \mathrm{~ms}$ in $\mathrm{CO}: \mathrm{CO}_{2}$ (45:55) atmosphere at $1735 \mathrm{~K}$.

(a)

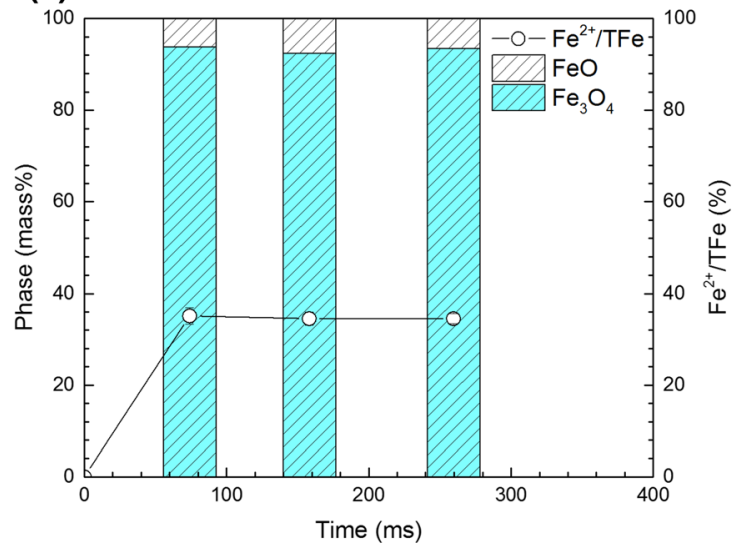

(b)

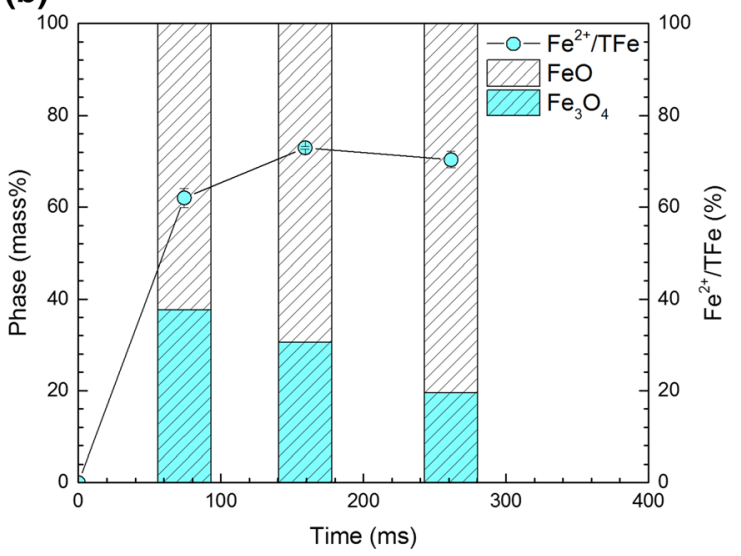

Fig. 3-Phase composition of iron ore particles with an average size of $110 \mu \mathrm{m}$ reacted in $(a) \mathrm{CO}^{\mathrm{C}} \mathrm{CO}_{2}(5: 95)$ and $(b) \mathrm{CO}: \mathrm{CO}_{2}(45: 55)$ atmosphere at $1735 \mathrm{~K}$

obvious difference in both $\mathrm{Fe}^{2+} / \mathrm{TFe}$ and phase composition, and the values of $\mathrm{Fe}^{2+} / \mathrm{TFe}$ keep at a relatively low level. The microscopic photos of particles with different sizes indicate the same conclusion. Figures 6 and 7 show that the reacted layer of the $244 \mu \mathrm{m}$ particles is much thinner than the other particles. The unreacted core of $142 \mu \mathrm{m}$ particles is also apparent, but its reacted layer is thick enough. While, the morphologies of 85 and $67 \mu \mathrm{m}$ particles are similar to each other: the unreacted hematite cores are already invisible in the particles.

\section{B. Crystallography}

The optical micrographs in Figure 1 indicate that the magnetite - wüstite coexisting particles had different topographic structures comparing to the hematitemagnetite coexisting particles. Usually, one magnetite-wüstite coexisting particle contained several visible unreacted magnetite cores inside. The cores shrunk during the reduction process. Meanwhile, the molten $\mathrm{FeO}$ invaded into the grain boundary of multi-grains. It raises a question whether the hematite ore particle was composed of multi-grains originally. In order to clarify the phase transformation mechanism of ore particles in reduction, especially the crystallographic relationship between hematite and magnetite, EBSD analysis was carried out on the particles. All of them contain lath magnetite. The results were shown in Figures 8, 9, and 10 .

Figures 8(b) and (c) are the inverse pole figures of different regional areas of the same partially reduced iron ore particle in Figure 8(a). The former region paralleled to the growth direction of the lath magnetite, and the phase boundary inside was mostly smooth. The later region contained a feather-like phase boundary inside. Both the two figures showed the (001) plane of hematite to the normal direction (ND), which implied that the hematite core is a single grain. Here, the ND is only for the convenience of description rather than any suggestion of a rolling process. Figure 8 indicates that the reduction process generated multi-grains of magnetite from single hematite grain. The sizes of the magnetite grains were an order of magnitude of $10 \mu \mathrm{m}$. There was no obvious difference between the magnetite grains formed on the feather-like phase boundary and the one not. Generally, the preferred crystallographic orientation between magnetite and hematite in the tested ore could be found as follows:

$$
(001)_{\text {Hematite }}||(111)_{\text {Magnetite }}
$$

which is the same as the results of many researchers. ${ }^{[18,19]}$ 
(a)

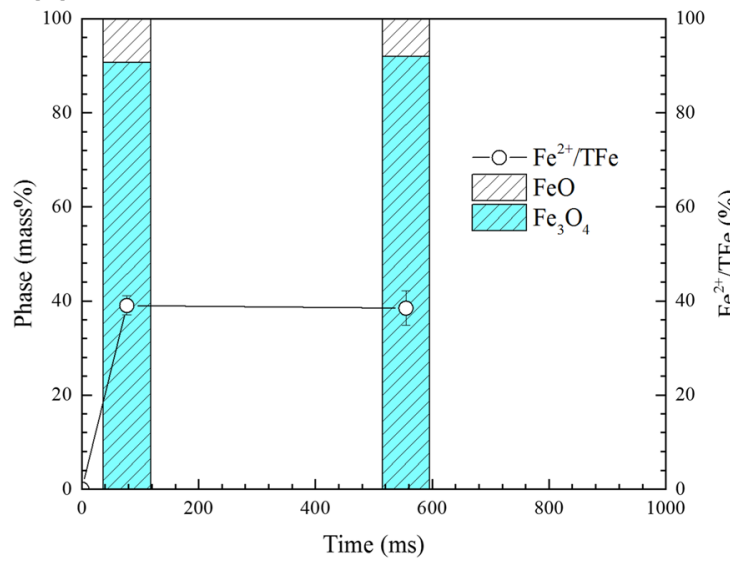

(b)

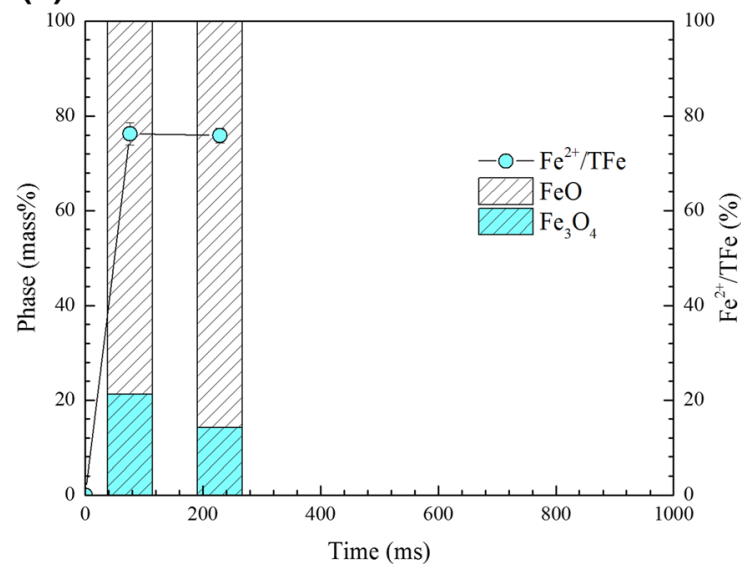

Fig. 4-Phase composition of iron ore particles with an average size of $85 \mu \mathrm{m}$ reacted in (a) $\mathrm{CO}: \mathrm{CO}_{2}(5: 95)$ and $(b) \mathrm{CO}: \mathrm{CO}_{2}(45: 55)$ atmosphere at $1735 \mathrm{~K}$.

(a)

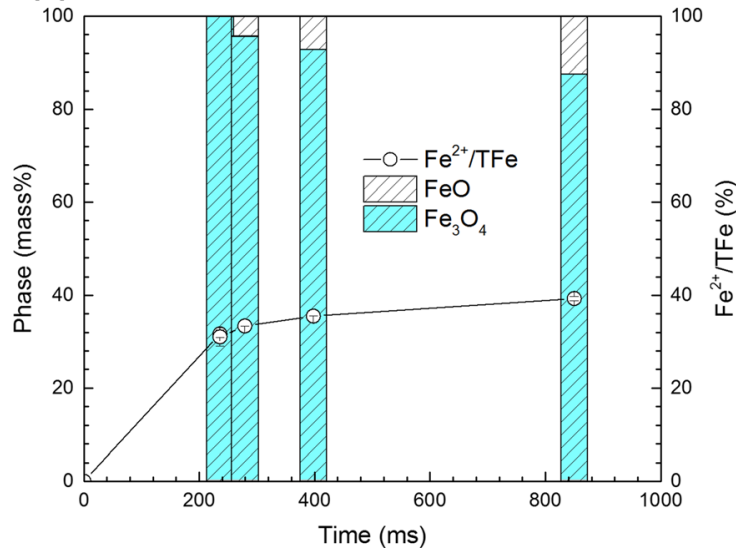

(b)

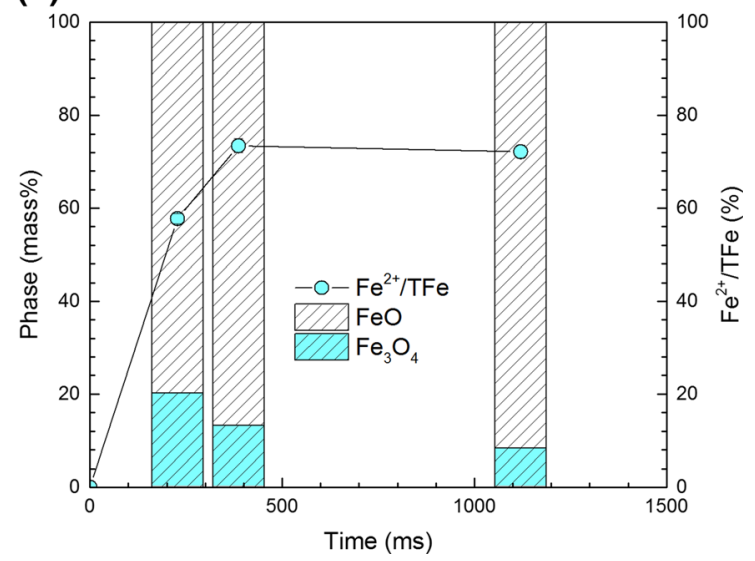

Fig. 5-Phase composition of iron ore particles with an average size of $67 \mu$ m reacted in (a) $\mathrm{CO}: \mathrm{CO}_{2}(5: 95)$ and $(b) \mathrm{CO}: \mathrm{CO}_{2}(45: 55)$ atmosphere at $1735 \mathrm{~K}$.

Table II. Phase Composition of Iron Ore Particles With an Average Size of 142 and $244 \mu \mathrm{m}$ Reacted in CO:CO Atmosphere at $1735 \mathrm{~K}$

\begin{tabular}{ccccccc}
\hline Size $/ \mu \mathrm{m}$ & $\mathrm{CO} / \mathrm{Vol} \mathrm{Pct}$ & $\mathrm{Time} / \mathrm{ms}$ & $\mathrm{Fe}^{2+} / \mathrm{TFe}(\mathrm{Pct})$ & $\mathrm{Fe}_{2} \mathrm{O}_{3} / \mathrm{wt} \mathrm{Pct}$ & $\mathrm{Fe}_{3} \mathrm{O}_{4} / \mathrm{wt} \mathrm{Pct}$ & $\mathrm{FeO} / \mathrm{wt} \mathrm{Pct}$ \\
\hline 142 & 5 & 75.1 & 17.0 & 0 & 98.5 & 1.5 \\
142 & 45 & 75.7 & 45.4 & 0 & 70.6 & 29.4 \\
244 & 5 & 78.3 & 5.4 & 82.9 & 0 \\
244 & 45 & 73.4 & 4.5 & 73.3 & 26.7 & 0 \\
\hline
\end{tabular}

Another inverse pole figure of a particle partially reduced in $\mathrm{CO}: \mathrm{CO}_{2}(45: 55)$ atmosphere was shown in Figure 9. The same structure can be observed in the Figures 8 and 9. The unreacted hematite core inside the particle was a single grain. And the formed magnetite was multi-grains.

The ore particle shown in Figure 10 was reduced more than the former particle in Figure 8. The hematite core was almost disappeared in the particle in Figure 10. Also, cracks of the particle were more pronounced than the former particle. Figure 10 clearly shows that around
40 magnetite grains transformed from one hematite grain in the particle. Boundaries of magnetite grains were shown in the figure too. Black lines were used when the orientation angle between the two adjacent grains was larger than $15^{\circ}$, which is defined as high-angle boundary. Figure 10 shows that high-angle boundary is the principal boundary in the partially reduced particle. Moreover, all the figures show that the magnetite grains are distributed uniformly in the particle. It implies that the magnetite nuclei were not only situated on the particle surface, but also in the inner area of the particle. 

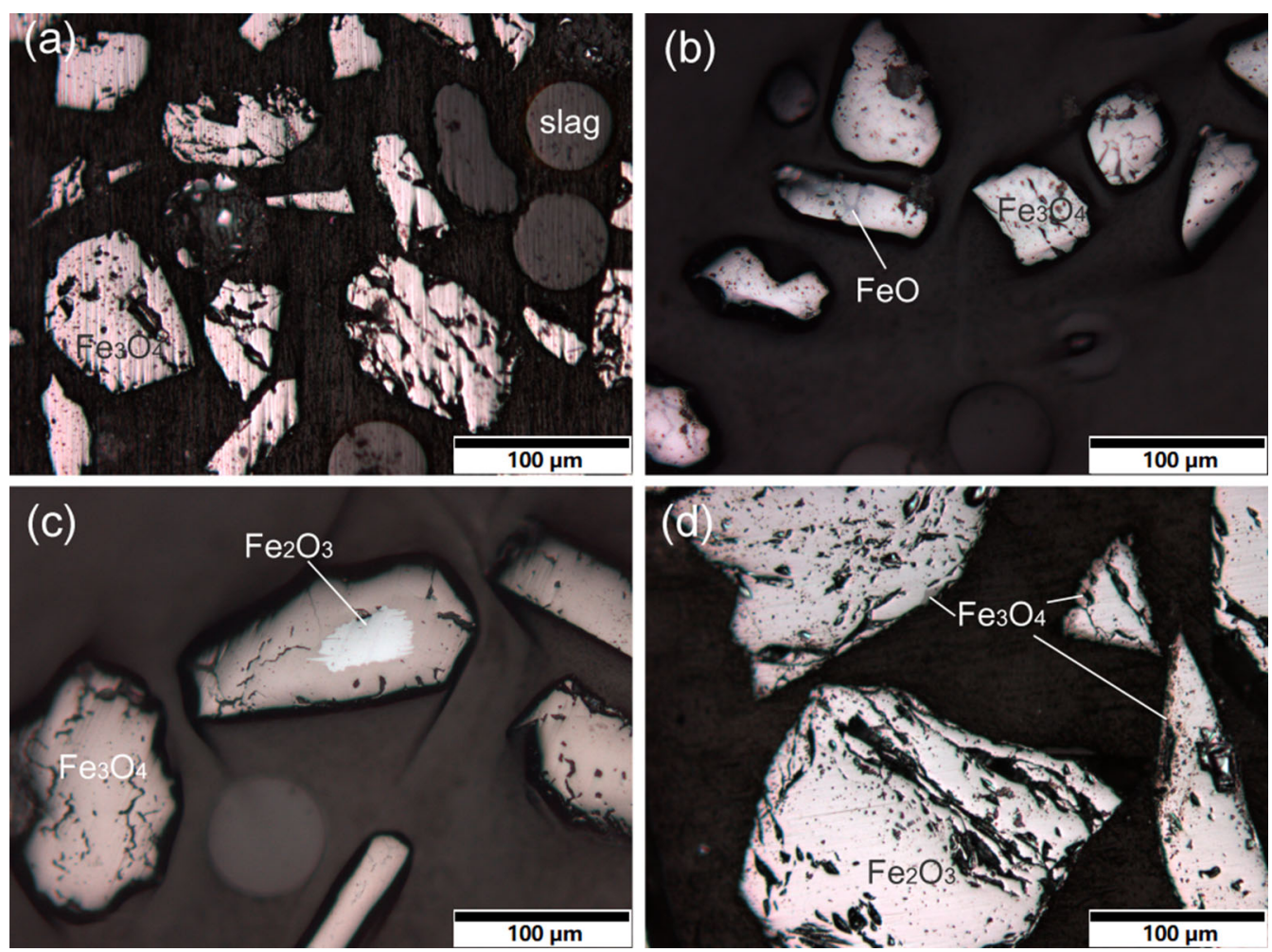

Fig. 6 - Cross section of samples with an average size of (a) $67 \mu \mathrm{m}$ reacted for $236 \mathrm{~ms}$; (b) $85 \mu \mathrm{m}(c) 142 \mu \mathrm{m}$ and $(d) 244 \mu \mathrm{m}$ reacted for around $77 \mathrm{~ms}$ in $\mathrm{CO}: \mathrm{CO}_{2}(5: 95)$ atmosphere at $1735 \mathrm{~K}$.
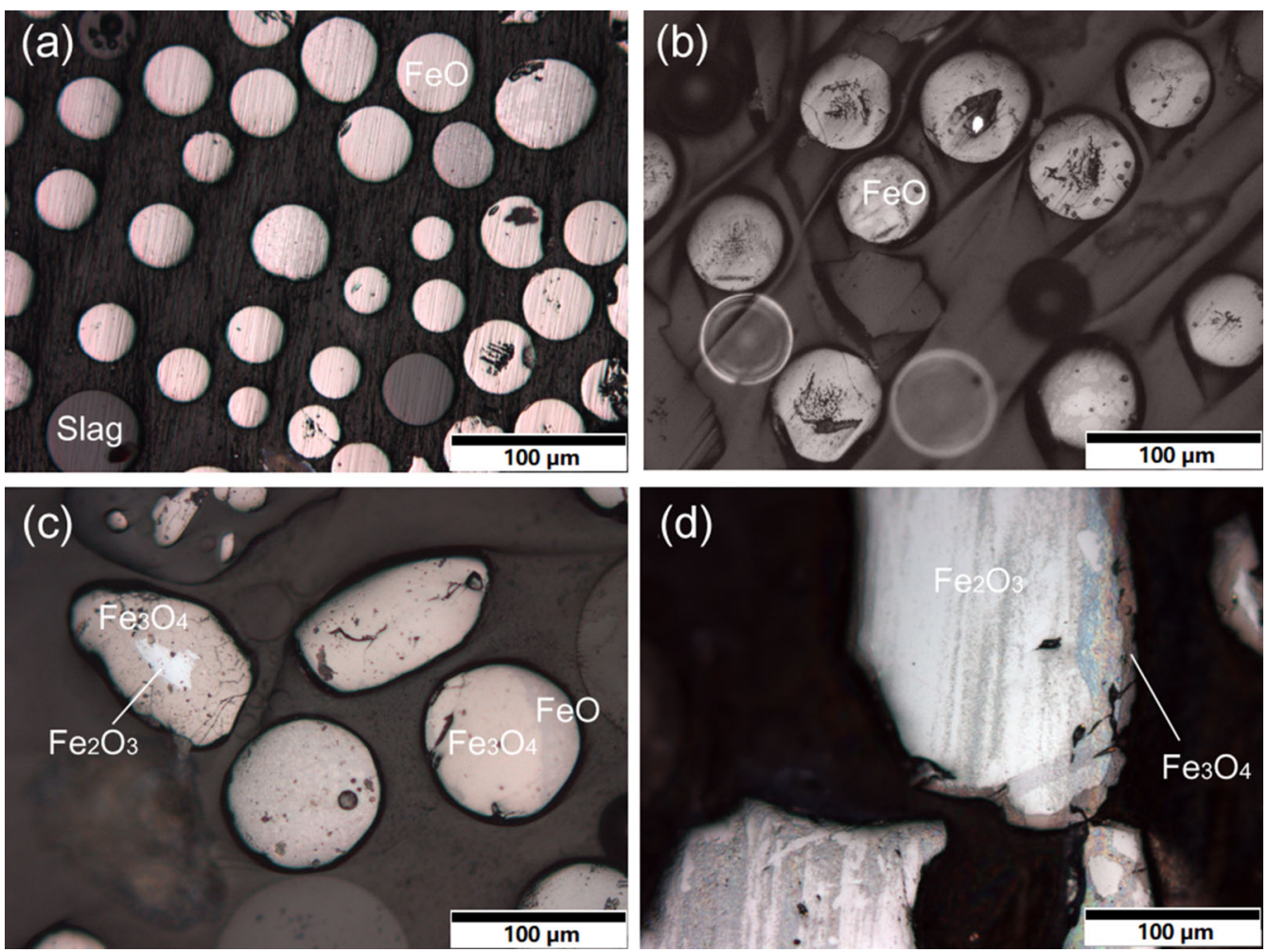

Fig. 7-Cross section of samples with an average size of (a) $67 \mu \mathrm{m}$ reacted for $228 \mathrm{~ms}$; (b) $85 \mu \mathrm{m} \mathrm{(c)} 142 \mu \mathrm{m}$ and (d) $244 \mu \mathrm{m}$ reacted around $75 \mathrm{~ms}$ in $\mathrm{CO}: \mathrm{CO}_{2}(45: 55)$ atmosphere at $1735 \mathrm{~K}$. 


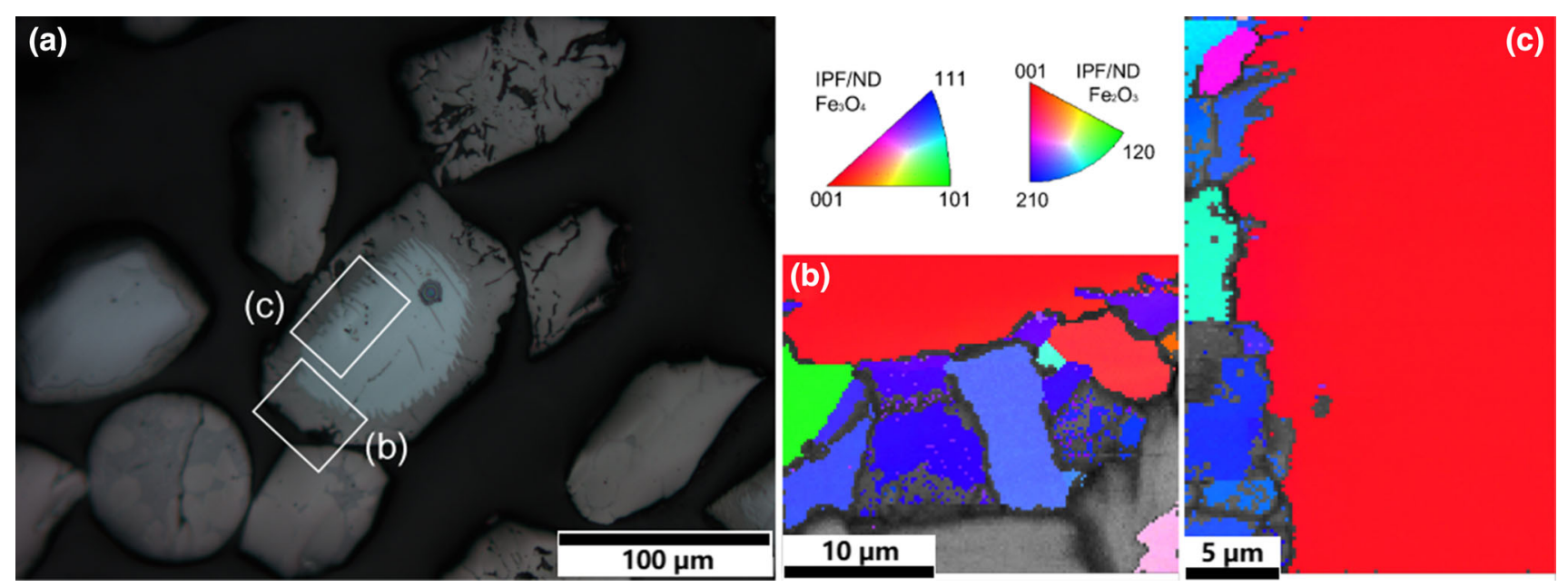

Fig. 8- Results of EBSD analyses of sample after reaction for $74 \mathrm{~ms}$ in $\mathrm{CO}: \mathrm{CO}_{2}(5: 95)$ atmosphere at $1735 \mathrm{~K}(a)$ cross section of particles; (b) and $(c)$ Inverse pole figures displaying crystal orientations parallel to the normal direction (ND).
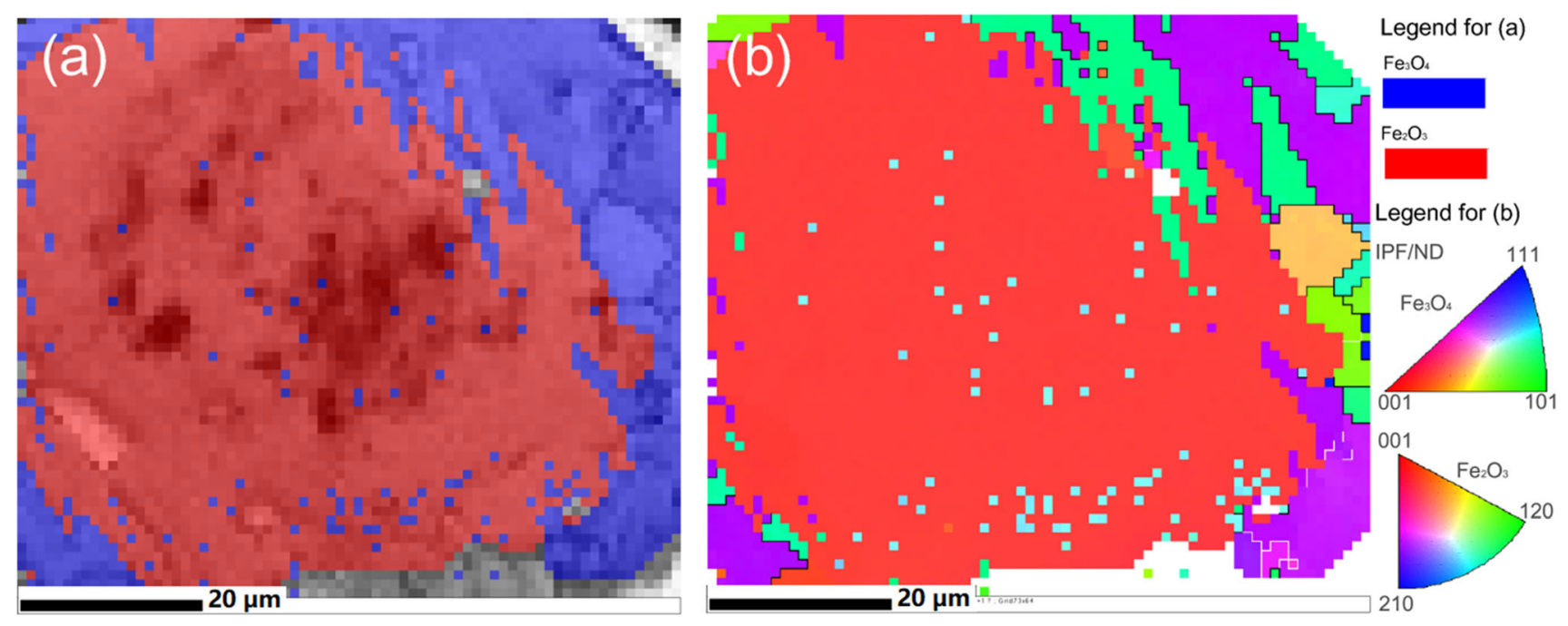

Fig. 9-Results of EBSD analyses of sample after reaction for $73 \mathrm{~ms}$ in $\mathrm{CO}: \mathrm{CO}_{2}$ (45:55) atmosphere at $1735 \mathrm{~K}(a)$ cross section of particles; $(b)$ Inverse pole figures displaying crystal orientations parallel to the normal direction (ND).

The former is surface nucleation, and the latter would suggest bulk nucleation. As an inference, bulk nucleation could be a dominant process in the reaction.

Figures 8(a) and 10 show some magnetite-wüstite containing particles around the analyzed particle. Those particles were in molten or semi-molten states. Figure 11 shows the EBSD analysis result of one of these particles. Darker values in the image quality map of Figure 11(a) indicate low image quality, potential grain boundaries. Because the crystal structures of magnetite and wüstite are cubic, there are few misjudgments of phase distribution in the particle. Combing the image quality map and the mineralogical distribution points, the results show that molten $\mathrm{FeO}$ invaded the particle through magnetite grain boundaries. Some of the inner magnetite grains in the particle had been reduced to be molten $\mathrm{FeO}$ in advance of outer grains. The EBSD results imply that the reduction from magnetite to wüstite contained two step: the rapid reduction of grain boundaries firstly, then each magnetite grain in the particle was reduced simultaneously. Based on the above, the overall picture of the reduction process of the particles used in this study can be established:

$$
\begin{aligned}
1^{\text {st }} \text { step : } & \text { single hematite grain } \\
& \rightarrow \text { shrinking hematite core } \\
& + \text { multi magnetite grains } \\
& \rightarrow \text { multi magnetite grains }
\end{aligned}
$$

$2^{\text {nd }}$ step : multi magnetite grains

$\rightarrow$ individual shrinking multi magnetite grains + molten $\mathrm{FeO}$ skeleton

$\rightarrow$ molten $\mathrm{FeO}$ 


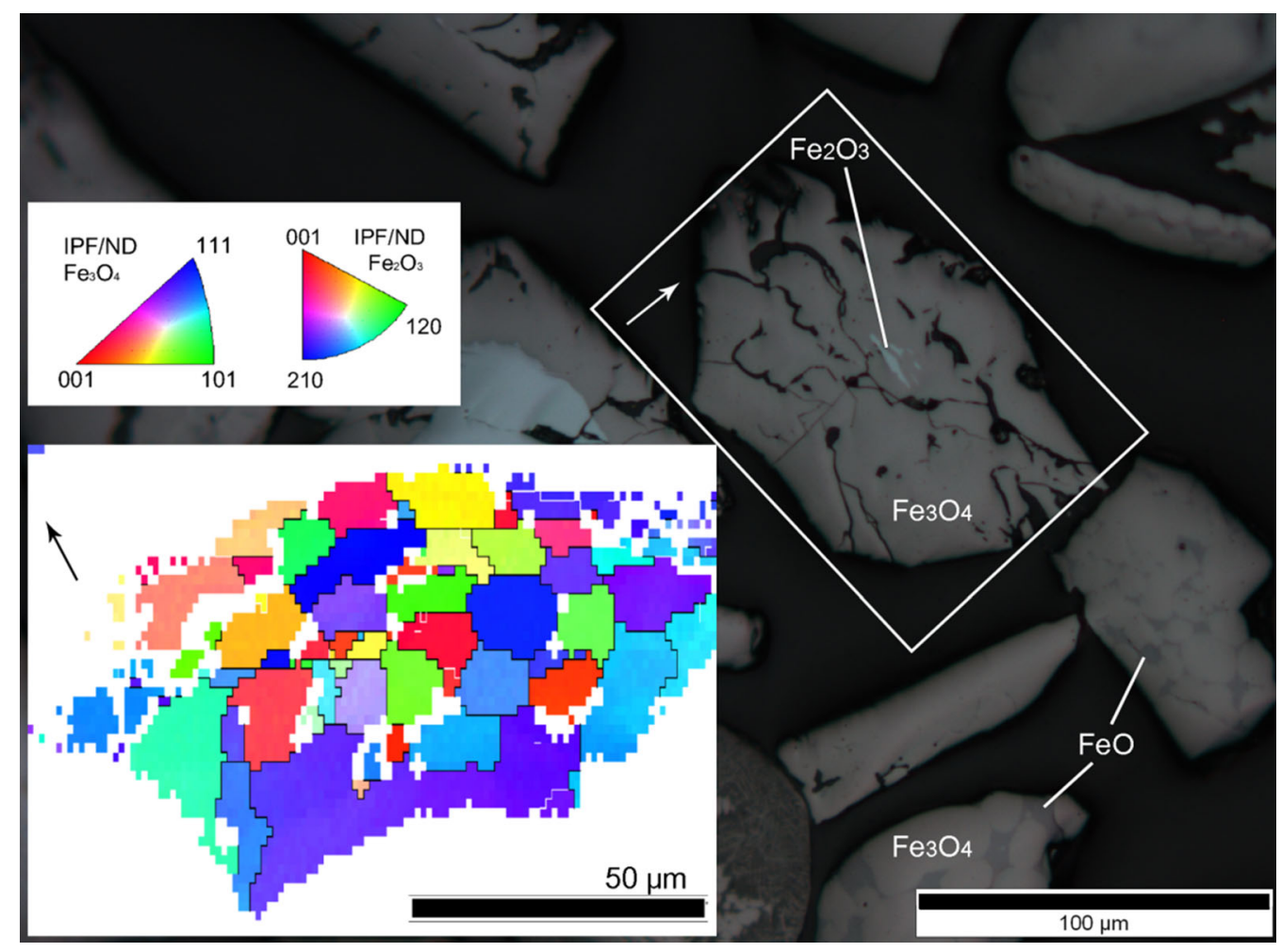

Fig. 10 - Cross section of particles of a particle after reaction for $74 \mathrm{~ms}$ in $\mathrm{CO}: \mathrm{CO}_{2}(5: 95)$ atmosphere at $1735 \mathrm{~K}$ and the corresponding inverse pole figure displaying crystal orientations parallel to the normal direction (ND), black lines were used when the orientation angle between the two adjacent grains is larger than $15^{\circ}$.
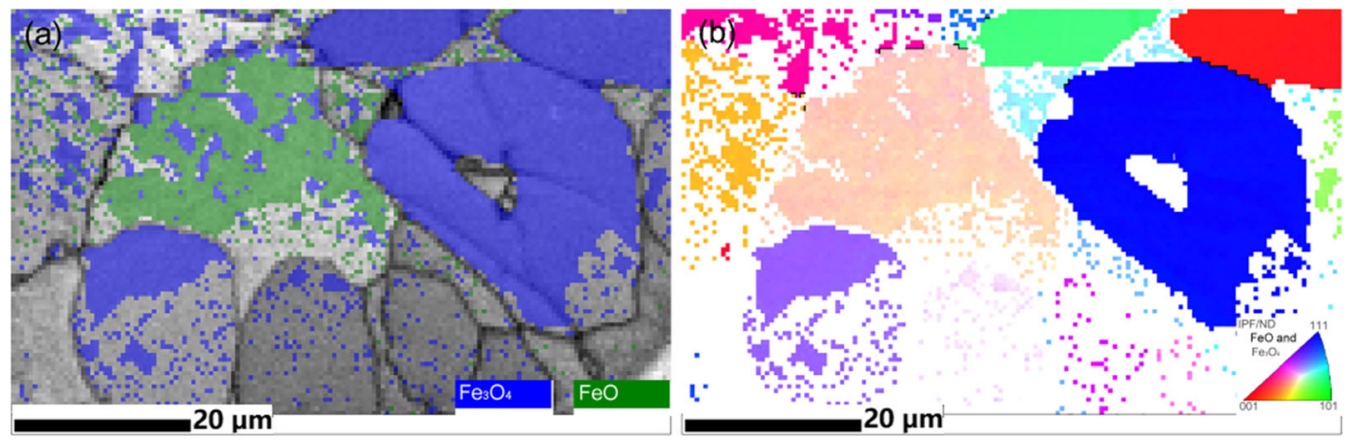

Fig. 11 - Cross section of a particle after reaction for $74 \mathrm{~ms}$ in $\mathrm{CO}: \mathrm{CO}_{2}(5: 95)$ atmosphere at $1735 \mathrm{~K}(a)$ image quality map and mineralogical distribution; $(b)$ inverse pole figure displaying crystal orientations parallel to the normal direction (ND).

Based on the chemical analysis results of $\mathrm{Fe}^{2+} / \mathrm{TFe}$, the reduction degree of iron ore was calculated, as shown in Figure 12. Firstly, the experimental results indicate that the reaction of particles with different particle sizes can reach the same level of reduction degree at the steady state (terminal point of the reaction). It is defined as $R_{\mathrm{t}}$. The values of $R_{\mathrm{t}}$ are 12.6 and 23.1 pet in $\mathrm{CO}: \mathrm{CO}_{2}(5: 95)$ and $\mathrm{CO}: \mathrm{CO}_{2}(45: 55)$ atmospheres, respectively. It is known that the reduction from hematite to magnetite and the reduction from magnetite to wüstite contribute 11.1 and $22.2 \mathrm{pct}$ removal of the total oxygen content in hematite. The same as the phase analysis, the main reduction in $\mathrm{CO}: \mathrm{CO}_{2}(5: 95)$ gas is the reduction from hematite, and wüstite became the principal phase in $\mathrm{CO}: \mathrm{CO}_{2}(45: 55)$ atmosphere.
The reactions were fast initially, and then slowed down or stopped within a short time. The extremely fast reaction rate implies that the reactivity of the sample in this study could be relatively high. On the one hand, the formation of lath magnetite, which was discussed in the last section, could extend the reaction interface between hematite and magnetite (Figure 8). On the other hand, the fast intrusion of molten $\mathrm{FeO}$ into gain boundaries of magnetite multi grains in one particle promotes the reduction process. Because of the rapid reaction rate and the limitation of equipment, the samples which react for shorter times cannot be collected. 
The reaction of 110 and $85 \mu \mathrm{m}$ particles were faster than the $67 \mu \mathrm{m}$ particles in both the two atmospheres. The reaction rates of particles with medium sizes were the highest in all the particles. The experimental results in Wang and Sohn's study ${ }^{[20]}$ indicated a similar tendency for the reduction of magnetite concentrate at $1423 \mathrm{~K}$ and $1473 \mathrm{~K}$. In their research, the reduction rate of magnetite concentrate particles increased with increasing particle size from 20 to $50 \mu \mathrm{m}$ at 1423 and $1473 \mathrm{~K}$. This investigation is different from the standard assumption that finer particles react faster. Usually, particles with smaller sizes have a higher specific surface area exposed to the reacting gas, resulting in a faster reaction rate. This deviation from normal behavior is explained in the next section.

\section{DISCUSSIONS}

\section{A. Kinetic Mechanism}

In the previous studies of the high-temperature reduction process of iron ore particles (above $1473 \mathrm{~K}$ ), researchers employed the Avrami-Erofeev equations or its revised form ${ }^{[20,21]}$ and the un-reacted shrinking core model (USCM) $)^{[3,11]}$ for the kinetic characterization. USCM and its revision are the most popular kinetic models in the pyro-metallurgical field for solid particle-gas reaction. ${ }^{[22-26]}$ According to different rate-determining step in the reduction kinetics, the isothermal reaction can be described by the following equations:

(1) Inner diffusion control model:

$$
1-\frac{2}{3} R-(1-R)^{2 / 3}=\frac{k_{\mathrm{GB}}}{r_{0}^{2}} t
$$

where, $k_{\mathrm{GB}}$ is the Ginstling-Brownshtein rate constant, which is proportional to the diffusion coefficient, ${ }^{[27]} r_{0}$ is the initial radius of the particle and $t$ is the reaction time.(2) Interfacial chemical reaction control:

(a)

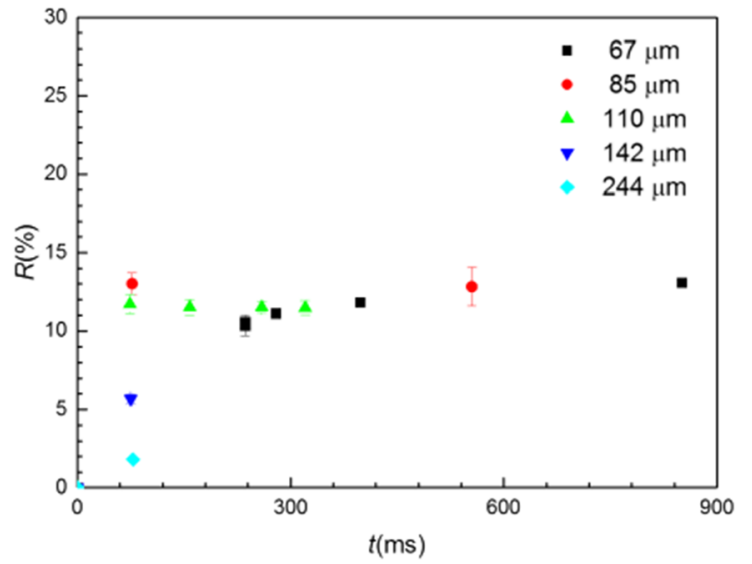

$$
1-(1-R)^{1 / 3}=\frac{k_{\mathrm{MK}}}{\rho_{0} r_{0}} t
$$

where $\rho_{0}$ is the oxygen density of the solid reactant, and $k_{\mathrm{MK}}$ is the McKewan rate constant. ${ }^{[28]}$

Based on the equations, the USCM was suggested to describe the relationship between particle size and apparent reaction rate constant of iron ore particles reduction as follows:

$$
k=\frac{k_{\mathrm{GB}}}{r_{0}^{2}}
$$

for inner diffusion control model; where, $k$ is the apparent rate constant.

$$
k=\frac{k_{\mathrm{MK}}}{\rho_{0} r_{0}}
$$

for interfacial chemical reactions. Equations [6] and [7] provide the representative relationships of particle size and reaction rate constant in USCM, that the value of $k$ increases with the decrease of $r_{0}$. However, our experimental results indicate the opposite tendency. Therefore, the reaction kinetics cannot be described by USCM.

The potential kinetic model may fulfill the conditions as follows:

(1) Larger initial specific surface area of the sample would not certainly lead to higher reaction rate;

(2) The reaction is a volumetric reaction rather than an interfacial reaction.

The first condition is obvious. The reason for the second condition is that, usually, a particle with a smaller size has a higher specific surface area exposed to the reacting gas, resulting in a faster interfacial reaction rate.

The most suitable kinetic process which can fit the two conditions is nucleation and growth. Hayes and Grieveson ${ }^{[16]}$ suggested the nucleation and growth process appears to be self-propagating. Usually, the rate

(b)

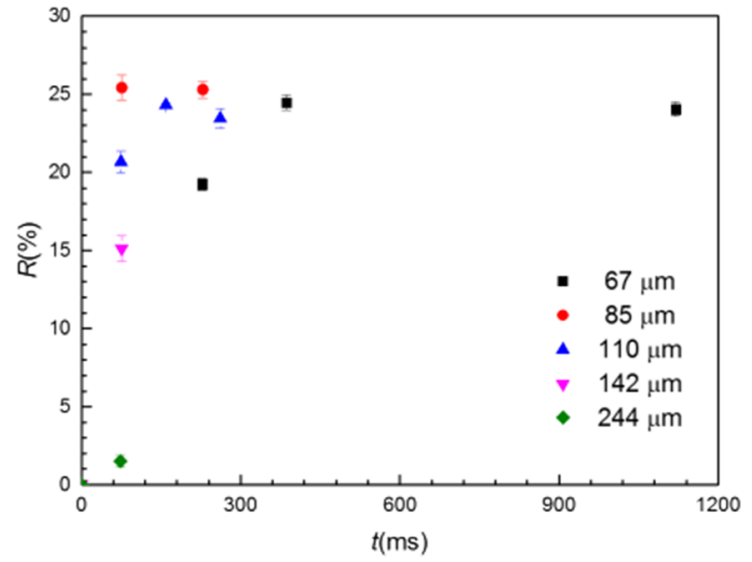

Fig. 12-Kinetic plots of hematite ore particle reduction with different sizes in (a) $\mathrm{CO}-\mathrm{CO}_{2}(5: 95)$ and $(b) \mathrm{CO}-\mathrm{CO}_{2}(45: 55)$ atmosphere at $1735 \mathrm{~K}$. 
of a self-propagating process could be promoted by enlarging particle size in that it is a volumetric reaction because of a boundary effect. Prout-Tompkins equation (P-T model $)^{[29,30]}$ is commonly used to describe the reaction kinetics of self-propagating process:

$$
R=\left[1+\exp \left(-k\left(t-t_{0}\right)\right)\right]^{-1}
$$

where, $t_{0}$ is the induction time of the logarithmic plot of the equation. It is suggested that the value of $k$ increases linearly with increasing $\mathrm{D}_{90}$ and $\mathrm{D}_{50}{ }^{[31]}$ and the average diameter. ${ }^{[32]}$ The study of Longuet and Gillard also indicates that the value of $k$ increase with increasing crystal size. ${ }^{[33]}$ There are several proposed explanations of the reason for the positive effect of particle size on the reaction rate constant:

(1) Ascending pore size between individual particles with increasing size in stacking, ${ }^{[34]}$ which would not be applied to the in-flight reaction process for the reason that the particles reacted individually in the reactor (please see the supporting information);

(2) Poison/catalyze effect of gaseous products ${ }^{[34]}$; It may not be the case in this study; To the best knowledge of the authors, there is no report about the poison/catalyze effect of $\mathrm{O}_{2}, \mathrm{H}_{2} \mathrm{O}$ and $\mathrm{CO}_{2}$ on the reduction kinetics of the iron oxides;

(3) Interference between nucleates happens earlier in smaller particles, ${ }^{[35,36]}$ which could be the main reason. As an illustration, once the frontier of the product nucleates collides, they stop in growth in this direction, and the growth rate of the nucleates decreases.

Comprehensively, many researchers pointed out that the rate constant reaches the maximum at a certain value of particle size. ${ }^{[36-40]}$ The particle size at the maximum rate constant is called the critical size. It is the same phenomenal description as our experimental results, which gives the evidence that the nucleation and growth process can be used to describe the kinetics in this study. While, there is a lack of explicit theoretical relationship between particle size and reaction rate constant in the Prout-Tompkins equation.

Another model that is used to describe nucleation and growth processes is the Johnson-Mehl-Avrami-Kolmogorov model (JMAK model). It is also named as Avrami-Erofeev equations, Kolmogorov-Johnson-Mehl-Avrami model or Kolmogorov-Erofeev-Kazeev-Avrami-Mampel model in different reports. ${ }^{[41,42]}$ In fact, the researchers pointed out that it is difficult to select between Prout-Tompkins and JMAK model kinetic models. ${ }^{[30,43]}$ The classical form of the JMAK model for volumetric nucleation and growth in three-dimensional space is as follows:

$$
R=1-\exp \left(-\frac{\pi}{3} N G^{3} t^{4}\right)
$$

where, $N$ is the rate of nucleation in $\mathrm{m}^{-3} \mathrm{~s}^{-1}, G$ is the rate of radial growth of the nuclei in $\mathrm{m} \mathrm{s}^{-1}$. An important assumption of this equation is that the system is infinite in extent, or to say there is no boundary for the system. In such condition, there is no any relationship between particle size and reaction rate constant. In a finite system, the nucleation can be divided into (outer) surface nucleation and bulk nucleation. Researchers ${ }^{[44,45]}$ indicated that a surface controlled transformation process dominates a fine-grained powder and a bulk transformation process results for a coarse one. It implies that the effect of surface/boundary can be significant for small particles. Therefore, there are a lot of studies making an effort to break the limitation of the above general equation. Considering that nuclei usually forms on surface, cracks and lattice imperfections, ${ }^{[39]}$ Johnson and Mehl proposed a sophisticated model to calculate how the surface nucleation affect the reaction kinetics ${ }^{[46]}$ for the value of a parameter $\lambda=a^{3} N / G$ no less than $3 \mathrm{~m}^{-1}$, where the $a$ is the grain size of the matrix in $\mathrm{m}$. Based on their model, Johnson and Mehl suggested that the increase of grain size would result in the increase of total reaction time but less time for the induction period. Later, Weinberg ${ }^{[44,47]}$ proposed an even more complex model to describe the nucleation and growth process both in bulk and at the surface. To simplify the model, he assumed the nucleation rate at the surface follows Dirac delta- function. Recently, Villa and Rios ${ }^{[48]}$ developed the model for surface and bulk nucleation for different shapes of the sample, where they provided two kinetic models considering site-saturated nucleation and constant nucleation rate, respectively. Take the expression for the bulk nucleation process with nucleation rate with $N_{1}$ is as an illustration ${ }^{[48]}$ :

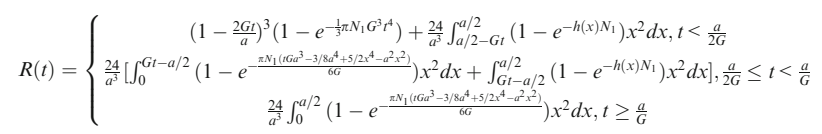

where

$$
\begin{array}{r}
h(x)=\frac{\pi}{60 G x}\left(\frac{5}{2} a^{2} G^{3} t^{3}+5 G t x^{4}-10 G^{3} t^{3} x^{2}-\frac{15}{16} a^{4} G t+10 G^{4} t^{4} x-\frac{15}{2} a^{2} G t x^{2}\right. \\
\left.5 a^{3} G t x-3 G^{5} t^{5}+5 a^{3} x^{2}-\frac{15}{8} a^{4} x-5 a^{2} x^{3}+\frac{1}{4} a^{5}+2 x^{5}\right)
\end{array}
$$

If we assume that $G=10$ unit length per unit of time and $N_{1}=100$ nuclei per unit volume per unit of time, one could obtain Figure 13(a) from Eq. [10]. It shows that the apparent reaction rate increases with the increasing size of the particle. If all the curves are fitted by the general JMAK model with the prior value of Avrami exponent, $n$ :

$$
[\ln (1-R)]^{1 / n}=-k t
$$

the equation can fit the curves with adjust coefficient of determination around 0.9996. It means that the nucleation and growth in the finite system can be described by the JMAK model. As Figure 13(b) shows, the Avrami exponent increases from 1 to 4 with the increase of particle size, and the apparent rate constant increases too. Also, when the value of Avrami exponent closes to 4 , the increase of apparent rate constant slows down. 
Figure 14 shows the curves of the expression for the surface nucleation process with nucleation rate with $\mathrm{N}_{2}{ }^{[48]}$ (There is a print error of the expression in the original publication.):

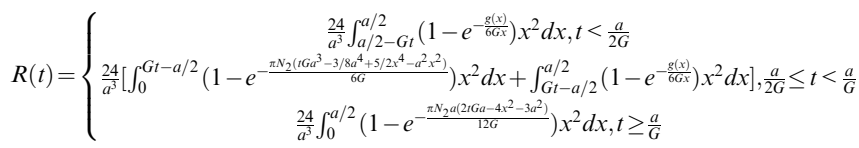

where,

$$
\begin{aligned}
g(x)= & \pi N_{2} a(G t-a / 2+x)\left(G^{2} t^{2}+G t a / 2-G t x-a^{2} / 2\right. \\
& \left.+2 a x-2 x^{2}\right)
\end{aligned}
$$

and $G=10$ unit length per unit of time and $N_{2}=$ 100 nuclei per unit area per unit of time. The nucleation at the surface of a very tiny particle follows a linear relationship with time, and the extremely large particle follows an exponential relationship with time. Eq. [12] can only fit the surface nucleation of the particle with medium sizes well, where the size is from 0.4 to 2. Figure 14 shows the fitting result of Eq. [12]. The apparent reaction rate constant increases with particle size firstly, and then decreases. At the same time, the value of the Avrami exponent keeps increasing.

Comparing Figures 13 and 14, the same as the previous studies, ${ }^{[4,45]}$ one could notice that the surface nucleation dominates the nucleation and growth process of small particles, and the bulk nucleation dominates the process of large particles. Moreover, due to the rate constant of bulk nucleation of large particles changes weakly with particle size, the relatively apparent decrease of the rate constant of surface nucleation of it could result in the decrease of the overall transform rate of the new phase in the particle. Globally, the overall reaction rate constant could act as a peak function of the particle size.

(a)

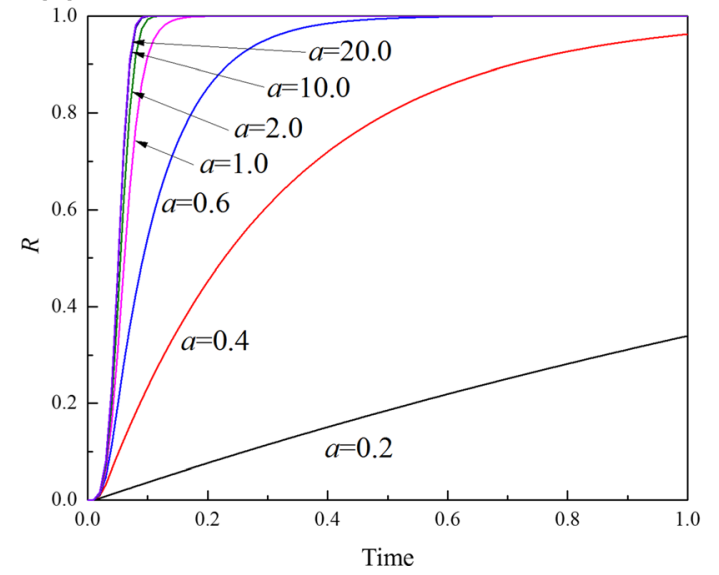

The JMAK model was successfully employed to simulate bulk nucleation and surface nucleation. The previous studies indicated the same treatment in kinetic analysis. Weinberg et al. ${ }^{[49]}$ suggested that for small surface seeding probability, one can obtain JMAK model, but the Avrami exponent is reduced due to finite-size effects. The theoretical study of Quiniou et al. ${ }^{[50]}$ gave the same suggestion. Furthermore, Alekseechkin $^{[51]}$ pointed out that the Avrami exponent decrease with time from 4 to 1 in homogeneous nucleation and 3 to 0 in specific heterogeneous nucleation in a particle with finite-size. Therefore, the JMAK model can be employed for modeling in our study.

\section{B. Modeling results}

The Avrami exponent for the JMAK model represents the dimensionality of the studied system. Usually, it is 4 for a three-dimensional nucleation and growth process. While, as described above, the Avrami exponent could be lower than 4 in practical applications. To testify the sensitivity of the fitting result to the value of Avrami exponent, the reduction of $67 \mu \mathrm{m}$ particle is presented here, for example. The Avrami exponent was chosen from 1 to 4 in that the process could be dominated by bulk nucleation and growth. The JMAK equations with different Avrami exponents fits the experimental data, and the adjusted coefficient of determination is from 0.9998 to 0.9999 except for $n=$ 1 , which is 0.9978 . Therefore, it is hard to determine which is the best equations to describe the reduction kinetics.

The morphology and crystallography of the cross-section of the partially reduced particles show that the shrinking rates of the hematite and magnetite cores in different directions are more or less in the same range. Moreover, most of the magnetite grains in the reduction process are not lath-shaped. This phenomenon implies that the nucleation and growth can be described as a three-dimensional process. The reduction degree data in Figure 12 means that the reaction rate of the particles with diameters of $85 \mu \mathrm{m}$ and $110 \mu \mathrm{m}$ could be similar.

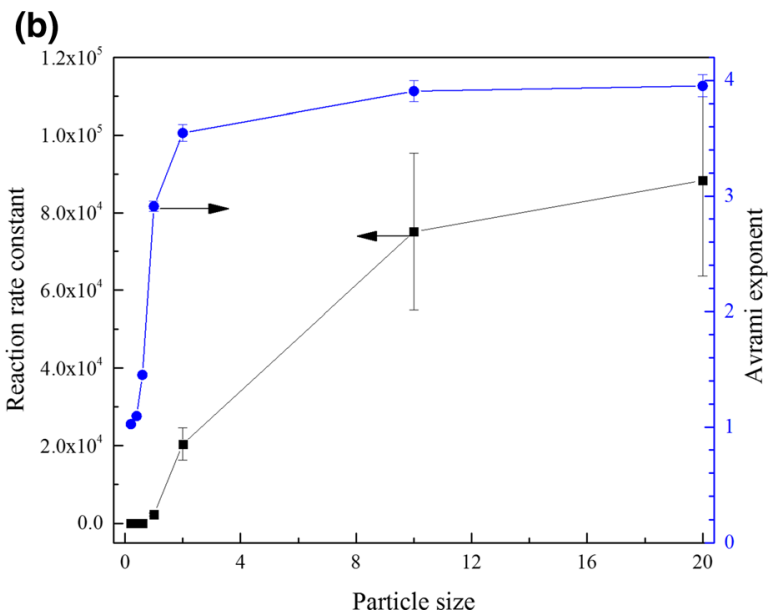

Fig. 13- Calculation example of the effect of particle size on the reaction kinetics in bulk nucleation, where the particle diameter and time are with units (a) Calculating results of Eq. [10] and (b) Fitting results of the curves in $(a)$ by Eq. [12]. 
(a)

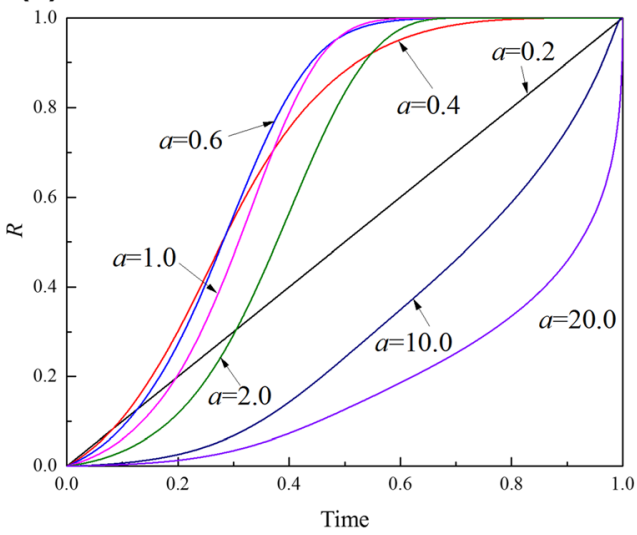

(b)

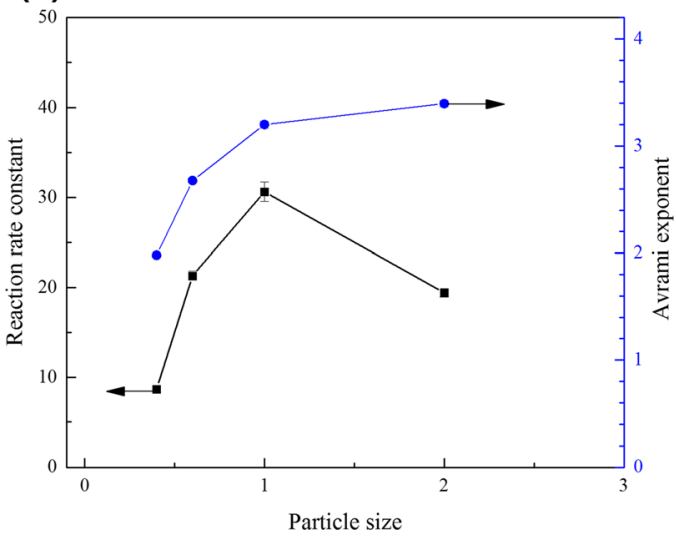

Fig. 14-Effect of particle size on the reaction kinetics in surface nucleation, where the particle diameter and time are with units (a) Calculating results of Eq. [13] and (b) Fitting results of the curves of particles with a from 0.4 to 2 in $(a)$ by Eq. [12].

Comparing the curve to Figure $13 \mathrm{~b}$, the nucleation and growth process of the particles with a diameter above $85 \mu \mathrm{m}$ could be treated as "large particles", for which the Avrami exponent is 4 for bulk nucleation. Due to the limitation of the experimental set-up, we lack enough reduction degree data for the very initial reduction stage within $200 \mathrm{~ms}$. As a result, Figure 15 shows that the JMAK model with different Avrami exponents can describe the existing data well. Therefore, an exact evaluation of the Avrami exponent value cannot be achieved now, and the above analysis implies that the adoption of $n=4$ for all the particles can be applied for the kinetic analysis in this work.

Figure 16 shows the fitting results of JMAK model with $n=4$. Variation of the rate constant with particle size is shown in Figure 17. It can be noted that the data of the $85 \mu \mathrm{m}$ particle in $\mathrm{CO}-\mathrm{CO}_{2}(45: 55)$ can only indicate the potential minimum value of the reaction rate constant. The rate constant of $67 \mu \mathrm{m}$ is the lowest in this study. Moreover, the relationship between rate constant and particle size follows a peak function, which is in agreement with the previous reports on the topics of nucleation and growth processes. Based on the last analysis, the increasing part of the reaction rate constant until $a=85 \mu \mathrm{m}$ is due to both the bulk and surface nucleation rates, which increase with increasing particle size. The rising value of $k$ could also be attributed to the self-propagating mechanism according to the above analysis. Moreover, the decreasing part is due to the decrease of surface nucleation rate. In the classical work of Mampel, ${ }^{[35]}$ it is suggested that for two specific conditions, the JMAK model can be simplified as:

$$
R(t)=\left\{\begin{array}{l}
1-c_{1} e^{-\pi N a^{2} t}, \text { where } k=\pi N a^{2}, \mathrm{t} \leq \frac{a}{2 G} \\
1-\left(1-\frac{2 G}{a} t\right)^{1 / 3}, \text { where } k=\frac{2 G}{a}, \mathrm{t} \geq \frac{a}{G}
\end{array}\right.
$$

where $c_{1}$ is the constant. It implies that the reaction rate constant follows a quadratic-relationship with particle size when the particle is small enough and follows an inverse relationship with particle size when the particle is large enough. Eq. [15] is employed to simulate the data variation in Figure 17 as follows:

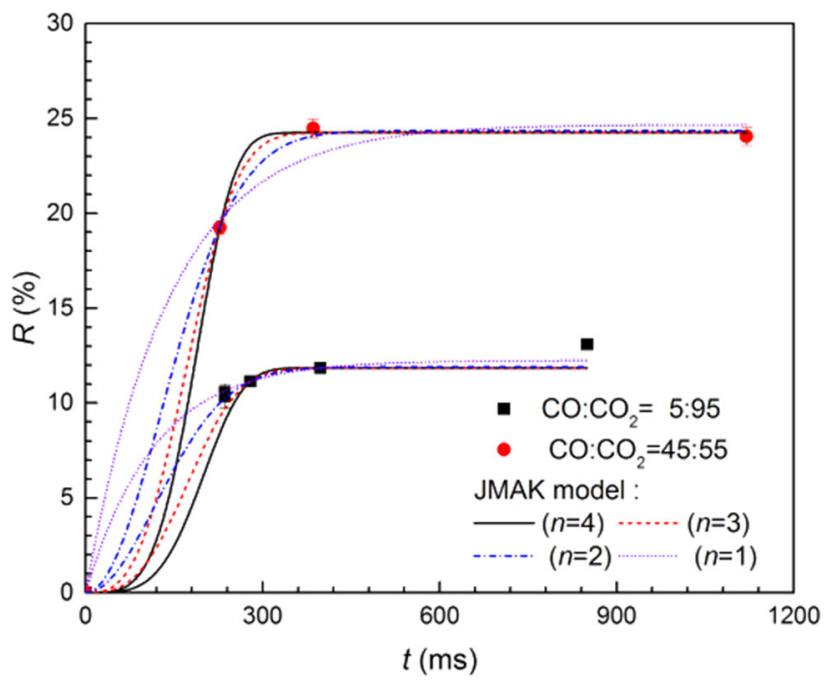

Fig. 15-Reduction degree of $67 \mu \mathrm{m}$ particle in two atmospheres and the fitting results of JMAK model with Avrami exponents of 1,2,3, and 4 .

For $\mathrm{CO}-\mathrm{CO}_{2}(5: 95)$ atmosphere:

$$
k=\left\{\begin{array}{c}
0.231 \times 10^{12} a^{2}, a \leq 85 \mu m \\
1.861 \times 10^{-3} a^{-1}, a \geq 85 \mu m
\end{array}\right.
$$

For $\mathrm{CO}-\mathrm{CO}_{2}(45: 55)$ atmosphere:

$$
k=\left\{\begin{array}{c}
0.215 \times 10^{12} a^{2}, a \leq 85 \mu m \\
1.675 \times 10^{-3} a^{-1}, a \geq 85 \mu m
\end{array}\right.
$$

In all the equations, the unit of particle size $a$ is meter. Figure 17 shows that both the Eqs. [16] and [17] cannot fit the data with $a \leq 85 \mu m$ well. It implies that the upper limit of the "small particle" in the above discussion should be lower than $85 \mu \mathrm{m}$, and the particles with a diameter above $85 \mu \mathrm{m}$ can be treated as "large particles". 
(a)

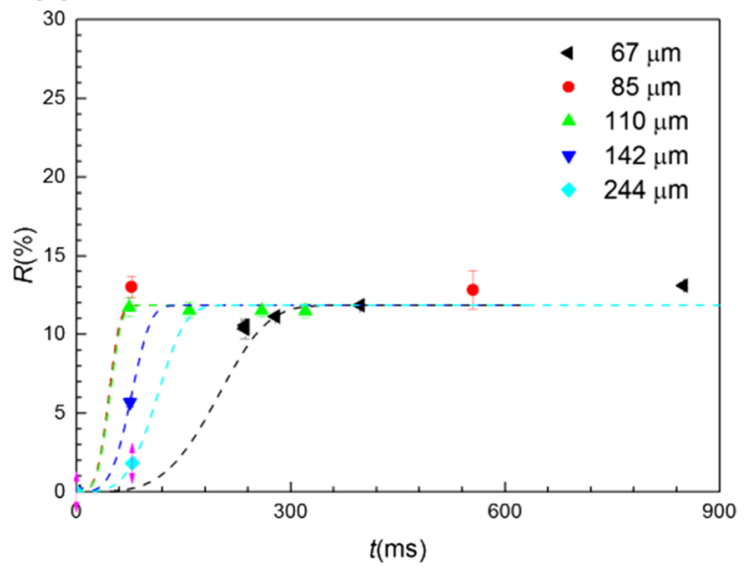

(b)

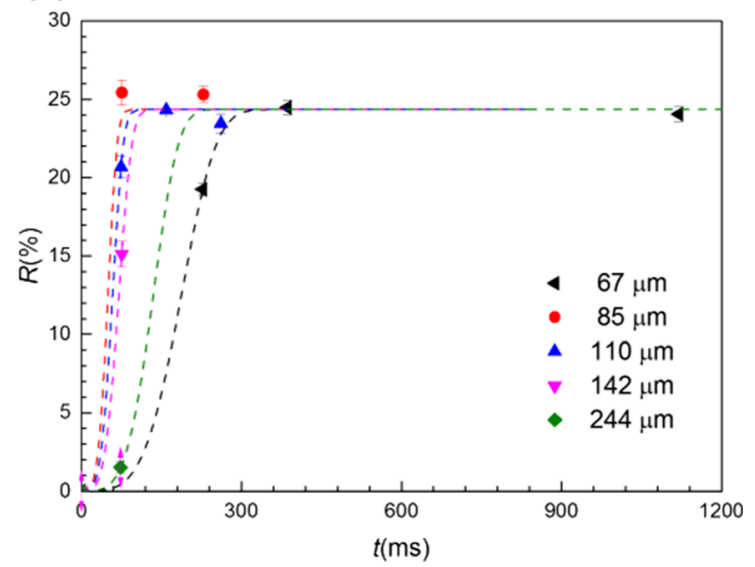

Fig. 16-Fitting results of JMAK model describing by Eq. [12] with Avrami exponent $\mathrm{n}=4$ for the hematite ore particle reduction with different sizes in $(a) \mathrm{CO}-\mathrm{CO}_{2}(5: 95)$ and $(b) \mathrm{CO}-\mathrm{CO}_{2}(45: 55)$ atmosphere at $1735 \mathrm{~K}$.

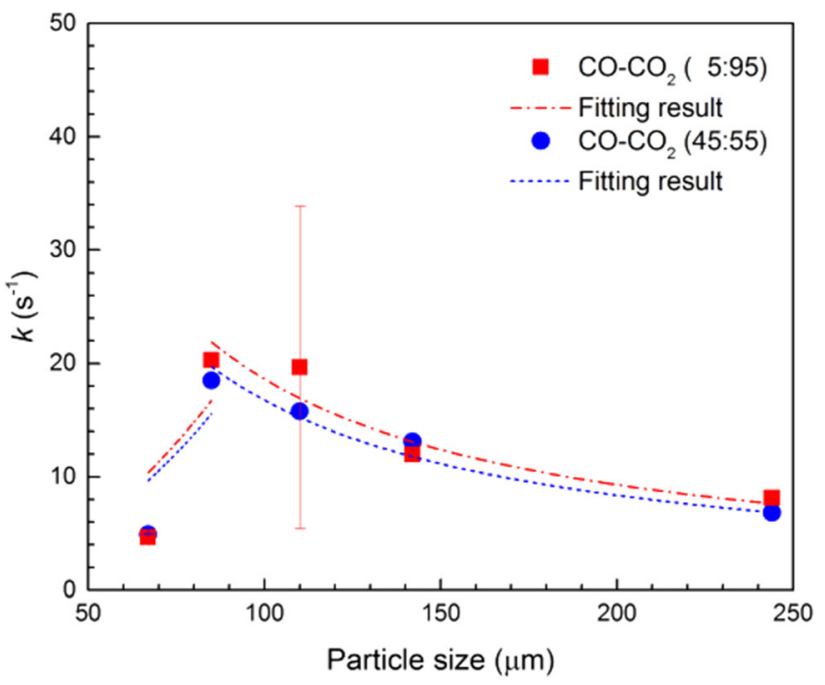

Fig. 17-Variation of reaction rate constant in the JMAK model describing by Eq. [12] $(\mathrm{n}=4)$ with the particle size. Also shown is the result of fitting the data with Eqs. [16] and [17].

\section{CONCLUSIONS}

Reduction of hematite ore particles in $\mathrm{CO}: \mathrm{CO}_{2}(5: 95)$ atmosphere at $1735 \mathrm{~K}$ followed the phase transformation from solid hematite to solid magnetite, and finally to molten $\mathrm{FeO}$. However, the mass ratio of wüstite in reduced particles was lower than 10 wt pct usually. Corresponding, the reduction degree was around 12.3 pct at the end of the reaction. Hematite particles reducing in $\mathrm{CO}: \mathrm{CO}_{2}(45: 55)$ atmosphere followed the same phase transformation sequence, except that the wüstite became the principal component in the reduced particles. Because of the high content of molten $\mathrm{FeO}$ (reduction degree around 25 pct at the end point), the reduced particles in $\mathrm{CO}: \mathrm{CO}_{2}(45: 55)$ atmosphere was sphere typically.
For this particular type of hematite ore particles, the particle transformed from single hematite crystal to multi-grains during the reduction. The size of the grains was an order of magnitude of $10 \mu \mathrm{m}$. These magnetite grains and hematite base preferred certain crystallographic orientations in the phase formation. During the reduction from magnetite to wüstite, the grain boundaries were quickly reduced first, then the individual magnetite grains in one particle gradually shrank during the reaction. The lath-magnetite formation and multi-grains transformation are suggested to be the reason for the acceleration of the reaction kinetics. The phase transformation phenomenon for other ores at the same conditions is suggested to be investigated to explore the general reduction mechanism.

A nucleation and growth mechanism was suggested to describe the reaction kinetics. The JMAK model with Avrami exponent of 4 was employed for the kinetic analysis. The reduction rate constant of particles in the two gas atmospheres followed a similar relationship with particle size: it increased with the particle size from 67 to $85 \mu \mathrm{m}$. It then slowly decreased as the particle size is further increased. The positive effect of particle size is recommended due to the self-propagating magnetite formation. The simulation results indicate that the reaction rate constant to particle size follows the inverse relationship when the particle size is above $85 \mu \mathrm{m}$.

\section{ACKNOWLEDGMENTS}

This research was carried out under project number T41.5.13489 in the framework of the Research Program of the Materials innovation institute (M2i) (ww w.m2i.nl) supported by the Dutch government. Mr. Dharm Jeet Gavel and Mr. Sander Van Asperen from TU Delft and Dr. Yingxia Qu from Northeastern University are acknowledged for the discussion, gas connection and the assembly of the set-up. We would like to express our thanks to Koen Meijer from Tata 
Steel Europe (IJmuiden) for fruitful discussions for this study. Mr. Kees Kwakernaak from Delft University of Technology is acknowledged for EBSD analysis and discussion. Mr. Ruud Hendrikx from Delft University of Technology is acknowledged for X-ray analysis. Mr. Michel van den Brink, Dr. Chenna Rao Borra and Mr. Prakash Venkatesan are acknowledged for ICP-AES analysis.

\section{OPEN ACCESS}

This article is licensed under a Creative Commons Attribution 4.0 International License, which permits use, sharing, adaptation, distribution and reproduction in any medium or format, as long as you give appropriate credit to the original author(s) and the source, provide a link to the Creative Commons licence, and indicate if changes were made. The images or other third party material in this article are included in the article's Creative Commons licence, unless indicated otherwise in a credit line to the material. If material is not included in the article's Creative Commons licence and your intended use is not permitted by statutory regulation or exceeds the permitted use, you will need to obtain permission directly from the copyright holder. To view a copy of this licence, visit http://creativec ommons.org/licenses/by/4.0/.

The online version contains supplementary material available at https://doi.org/10.1007/s11663-021-02173-y.

\section{REFERENCES}

1. K. Meijer, M. Denys, J. Lasar, J.-P. Birat, G. Still, and B. Overmaat: Ironmak. Steelmak., 2009, vol. 36, pp. 249-51.

2. K. Meijer, C. Zeilstra, C. Teerhuis, M. Ouwehand, and J. van der Stel: Trans. Ind. Inst. Metals, 2013, vol. 66, pp. 475-81.

3. Y. Qu, Experimental Study of the Melting and Reduction Behaviour of Ore Used in the HIsarna Process (PhD thesis), Delft University of Technology, Delft, The Netherlands, 2013.

4. Y. Qu, Y. Yang, Z. Zou, C. Zeilstra, K. Meijer, and R. Boom: ISIJ Int., 2014, vol. 54, pp. 2196-2205.

5. Y. Qu, Y. Yang, Z. Zou, C. Zeilstra, K. Meijer, and R. Boom: ISIJ Int., 2015, vol. 55, pp. 149-57.

6. Y. Qu, Y. Yang, Z. Zou, C. Zeilstra, K. Meijer, and R. Boom: Ironmak. Steelmak., 2015, vol. 42, pp. 763-73.

7. L. Guo, J. Gao, S. Zhong, Q. Bao, and Z. Guo: J. Iron Steel Res. Int., 2018, vol. 60, pp. 1-17.

8. A. Bunjaku, M. Kekkonen, K. Pietilä, and P. Taskinen: Miner. Process. Extr. Metall., 2012, vol. 121, pp. 156-65.

9. A. Thurnhofer, M. Schachinger, F. Winter, H. Mali, and J.L. Schenk: ISIJ Int., 2005, vol. 45, pp. 151-58.

10. A. Pineau, N. Kanari, and I. Gaballah: Thermochim. Acta, 2007, vol. 456, pp. $75-88$.

11. Y. Qu, Y. Yang, Z. Zou, C. Zeilstra, K. Meijer, and R. Boom: ISIJ Int., 2015, vol. 55, pp. 952-60.

12. Z. Chen, Y. Qu, C. Zeilstra, J. Van Der Stel, J. Sietsma, and Y. Yang: J. Iron Steel Res. Int., 2019, vol. 26, pp. 1285-94.

13. W. Zhang, J. Zhang, Z. Zou, Q. Li, and Y. Qi: Ironmak. Steelmak., 2014, vol. 41, pp. 715-20.

14. W. Zhang, J. Zhang, Q. Li, Y. He, B. Tang, M. Li, Z. Zhang and Z. Zou, In Proceedings of the 8th Pacific Rim International Con- gress on Advanced Materials and Processing, ed. Fernand Marquis (Springer International Publishing: Cham, 2016), pp 777-89.

15. Z. Chen, C. Zeilstra, J. Van Der Stel, J. Sietsma, and Y. Yang: Ironmak. Steelmak., 2020, vol. 47, pp. 741-47.

16. P. Hayes and P. Grieveson: Metall. Trans. B, 1981, vol. 12B, pp. 579-87.

17. P. Baguley, D.H.S. John, and P. Hayes: Metall. Mater. Trans. B, 1983, vol. 14B, pp. 513-14

18. Y. Kashiwaya, Y. Yamaguchi, H. Kinoshita, and K. Ishii: ISIJ Int., 2007, vol. 47, pp. 226-33.

19. Y. Watanabe, S. Takemura, Y. Kashiwaya, and K. Ishii: J. Phys. $D$, 1996, vol. 29 , p. 8 .

20. H. Wang and H. Sohn: Metall. Mater. Trans. B, 2013, vol. 44B, pp. 133-45.

21. H. Wang. Reduction kinetics of iron ore concentrate particles relevant to a novel green ironmaking process ( $p h D$ thesis). University of Utah, Salt Lake, USA, 2011.

22. M. Ishida, C. Wen, and T. Shirai: Chem. Eng. Sci., 1971, vol. 26, pp. $1043-48$

23. M. Ishida and C.Y. Wen: Chem. Eng. Sci., 1971, vol. 26, pp. 103141.

24. V. Safari, G. Arzpeyma, F. Rashchi, and N. Mostoufi: Int. J. Miner. Process., 2009, vol. 93, pp. 79-83.

25. T. Usui, Y. Nakamuro, M. Nishi, M. Naito, H. Ono, and P.S. Assis: Tetsu-to-Hagane, 2014, vol. 100, pp. 294-301.

26. A.Z. Ghadi, M.S. Valipour, and M. Biglari: Ironmak. Steelmak., 2016, vol. 43, pp. 418-25.

27. A. Ginstling and B. Brounshtein: J. Appl. Chem. USSR, 1950, vol. 23, pp. 1327-38.

28. W.M. McKewan: Trans. Am. Inst. Min. Metall. Eng., 1960, vol. 218 , pp. 2-6.

29. E. Prout and F.C. Tompkins: Trans. Faraday Society, 1944, vol. 40 , pp. $488-98$

30. M.E. Brown: Thermochim. Acta, 1997, vol. 300, pp. 93-106.

31. M. Dunne, O. Corrigan, and Z. Ramtoola: Biomaterials, 2000, vol. 21, pp. 1659-68.

32. M.J. John, K. Muraleedharan, M. Kannan, V.A. Mujeeb, and T.G. Devi: Thermochim. Acta, 2012, vol. 534, pp. 64-70.

33. B. Longuet and P. Gillard: Propellants Explos. Pyrotech., 2009, vol. 34 , pp. 59-71.

34. L. Bircumshaw and B. Newman: Proc. R. Soc. Lond. A, 1955, vol. 227 , pp. $228-41$.

35. L. MampelKurt: Z. Phys. Chem., 1940, vol. 187A, p. 235.

36. V.R.P. Verneker, K. Kishore, and M.P. Kannan: J. Chem. Technol. Biotechnol., 1977, vol. 27, pp. 309-17.

37. L.L. Bircumshaw and B.H. Newman: Proc. Math. Phys. Eng. Sci., 1955, vol. 227, pp. 228-41.

38. K. Muraleedharan, V.M.A. Mujeeb, M.H. Aneesh, T. Gangadevi, and M.P. Kannan: Thermochim. Acta, 2010, vol. 510, pp. 160-67.

39. S. Gregg and R. Razouk: J. Chem. Soc., 1949, pp. 36-44.

40. C.J. Chou and F.A. Olson: Anal. Chem., 1972, vol. 44, pp. 184144.

41. K. Barmak: Metall. Mater. Trans. A, 2010, vol. 41A, pp. 2711-75.

42. M. Hillert: Metall. Mater. Trans. A, 2011, vol. 42, p. 3241.

43. D. Broadbent, J. Dollimore, D. Dollimore, and T.A. Evans: $J$. Chem. Soc. Faraday Trans., 1991, vol. 87, pp. 161-66.

44. M.C. Weinberg: J. Non Cryst. Solids, 1992, vol. 142, pp. 126-32.

45. C.S. Ray, W. Huang, and D.E. Day: J. Am. Ceram. Soc., 1991, vol. 74 , pp. $60-66$.

46. J. William and R. Mehl: Trans. Metall. Soc. AIME, 1939, vol. 135, pp. 416-42.

47. M.C. Weinberg: J. Non Cryst. Solids, 1991, vol. 134, pp. 116-22.

48. E. Villa and P.R. Rios: Acta Mater., 2010, vol. 58, pp. 2752-68.

49. M.C. Weinberg, D.P. Birnie III and V.A. Shneidman: J. NonCryst. Solids, 1997, vol. 219, pp. 89-99.

50. T. Quiniou, M. Meyer, and F. Rocca: Physica B, 2014, vol. 440, pp. 53-60.

51. N.V. Alekseechkin: Condens. Matter Phys., 2008, vol. 11, pp. 597613.

Publisher's Note Springer Nature remains neutral with regard to jurisdictional claims in published maps and institutional affiliations. 